\title{
Examining the Socioeconomic Determinants of Adoption of the 'Government Gateway' Initiative in the UK
}

\section{Yogesh Kumar Dwivedi*}

School of Business and Economics, Swansea University, Singleton Park, Swansea, SA2 8PP, Wales, UK. E-mail: ykdwivedi@gmail.com

*Corresponding Author

\section{Anastasia Papazafeiropoulou}

School of Information systems computing and mathematics, Brunel University, Uxbridge, Middlesex, UB8 3PH, UK

E-mail: Anastasia.papazafeiropoulou@brunel.ac.uk

\section{Hosein Gharavi}

School of Management Information Systems, Faculty of Business and Law, Edith Cowan University, Perth, Western Australia. E-mail:

h.gharavi@ecu.edu.au

\section{Khalil Khoumbati}

School of Information systems computing and mathematics, Brunel University, Uxbridge, Middlesex, UB8 3PH, UK. E-mail: Khalil.Khoumbati@gmail.com

\begin{abstract}
This paper empirically examines the impact of socioeconomic determinants upon the adoption of a recent UK e-Government initiative, the 'Government Gateway'. Five socio-economic characteristics that provide insights to Government Gateway adopters and non-adopters, as they were identified from the literature review used in this study. These included age, gender, education, income and occupation. The data on these variables was collected on a nationwide scale employing a postal survey. A self-administered questionnaire was sent to 1600 households with a total of 358 responses obtained from the respondents. The findings of this research suggest that the three variables of age, gender and occupation significantly differentiated the adopters from the nonadopters of the Government Gateway, whilst education and income were found to be non-significant. The implications of the findings are discussed in the context of promoting the adoption of emerging ICT technologies such as broadband and reducing the digital divide against less privileged parts of the population.
\end{abstract}

Keywords: Government Gateway, Adoption, Socio-economic Characteristics, Citizens, United Kingdom. 
Reference to this paper should be made as follows: Dwivedi, Y.K., Papazafeiropoulou, A., Gharavi, H. and Khoumbati, K. (2006) 'Examining the Socioeconomic Determinants of Adoption of an E-government Initiative, the 'Government Gateway', Electronic Government: An International Journal, Vol. 0, No 0, pp.00-00.

Biographical notes: Yogesh Dwivedi is a Lecturer in the School of Business and Economics, Swansea University. He obtained his $\mathrm{PhD}$ on 'Investigating consumer adoption, usage and impact of broadband: UK households' and an MSc in Information Systems from Brunel University. His research interests include the adoption, usage and impact of telecommunication technologies, the Internet and e-commerce. He has co-authored more than 20 papers in academic journals and international conferences. He is a member of the Association of Information Systems (AIS) and Life Member of Global Institute of Flexible Systems Management, New Delhi.

Anastasia Papazafeiropoulou is a lecturer at the Information Systems and Computing department at Brunel University, UK. She has received her PhD, titled: "A stakeholder approach to electronic commerce diffusion", from the same university. She has worked as a technical trainee in the European Union (EU) in Brussels and as a research associate with expertise in electronic commerce at the Athens University of Economics and Business and Brunel University. She holds a first degree in Informatics (1994, Athens University of Economics and Business, Greece) and a M.Sc. in Information Systems (1997, Athens University of Economics and Business, Greece). Her research interests fall within social aspects and policy issues related to the diffusion and adoption of information technologies. The domain areas she is actively involved are: electronic commerce, broadband Internet, Enterprise Resource Planning Systems (ERPs) and healthcare.

\section{Hosein Gharavi is a....}

Khalil Khoumbati is a researcher in the Department of Information Systems and Computing at Brunel University. His current research focus is on the adoption of enterprise application integration in healthcare organizations. He holds MSc in Information Technology and a Bachelor's degree in Electronics, both from Institute of Information Technology, University of Sindh. He has published several research papers in internationally refereed journals and international conferences such as HICSS, AMCIS, ECIS and EMCIS.

\section{Introduction}

E-government encompasses a broad spectrum of activities that are offered using Information and Communication Technologies (ICTs) and allows an improved service of the government to citizens (Northrup and Thorson, 2003). There are 
many substantial benefits of e-government including: (1) reductions in cost for both businesses and governments by cutting the tax burden and boosting competitiveness; (2) with the help of the e-government the public sector can be made more open and transparent, delivering governments which are more comprehensible and accountable to citizens, improving civic involvement in policy making and reinforcing democracy at every level across Europe; and (3) administrations can be made more citizen-centered and inclusive, providing 24/7 personalised services to everyone, no matter what their circumstances or their special needs are (Yttersad and Watson, 1996).

The field of e-government is a new and emerging one for researchers, especially when investigating the adoption pattern. The early research in this area has focused mainly upon the supply side or government related issues such as strategies and policy (Chadwick and May, 2003); challenges (Yang and Paul, 2005); technical issues (Bose, 2004; George, 2004) and evaluation of the usability of e-government websites (Choudrie et al., 2004). However, little attention has been given to the demand from a citizens' perspective. Recent studies that addressed the citizens' view on e-government services suggest that trust, security and transparency (Marche and McNiven, 2003) are the major issues for e-government adoption.

Gefen et al. (2002) studied the adoption of online government services employing data collected from the undergraduate students of three Universities. The findings of this study suggest that trust, social influence, and website easeof-use impact the perceived usefulness of the interface, which, combined with social influence, predict the intended use of e-government. Carter and Belanger's study (Carter and Belanger, 2004) suggests that the relative advantage, image, compatibility and perceived usefulness are constructs that are important in explaining the citizens' perception of e-government adoption (Carter and Belanger, 2004). The aforementioned studies were initial attempts to examine factors such as trust, transparency, compatibility and relative advantage, which affect the adoption of e-government services by the citizens of countries other than the United Kingdom. Literature analysis suggests that such studies are not yet performed to investigate the adoption rate and behaviour of the UK citizen. This is because e-government related development is new and recent to the UK.

A report on benchmarking e-government in Europe and the US suggested that 'existing studies of e-government concentrate on the supply-side by focusing on the availability and level of sophistication of online services and usage' (RAND EUROPE, 2003). The findings from this report reveal that citizens are reluctant to utilise those e-government services that require personal information. These findings also suggest that 'among respondents who indicated a preference for online government services, citizens were not always aware of which government services were available online' (RAND EUROPE, 2003). This report covered only a few aspects of the demand-side of e-government and recommended "future research is essential to get a more complete picture of the perceptions and attitudes of the users of e-government services. Also, analyzing 
why results per service or per country differ is of great interest for policy makers" (RAND EUROPE, 2003).

Also, as novel forms of ICTs (i.e. e-government services) are being adopted, the equitable distribution of ICTs has become an issue of concern. The apprehensions are being attributed to social exclusions that could arise due to the inequitable dissemination, which in turn could lead to citizens with lower incomes or educational levels not having access to information technology, thereby resulting in a digital divide (Ifinedo and Davidrajuh, 2005; Mason and Hacker, 2003; Yu and Wang, 2004). As Personal Computer (PC) and the Internet became prevalent in society, the issue then turned into whether these newer forms of technology such as e-government were dividing society into two segments (Ifinedo and Davidrajuh, 2005; Mason and Hacker, 2003; Yu and Wang, 2004). Whilst the earlier forms of research examined technologies such as PCs and the Internet, more recent research has begun to understand the issues related with emerging e-government services.

Similar to other global e-government measures being undertaken, the United Kingdom (UK) government is also embarking upon measures that ensure it is in accordance with other countries around the globe. For this purpose, the introduction and experiences of utilising a number of government services that are offered electronically via the 'Government Gateway' in the UK is pertinent (Gov Gateway). This novel phenomenon offers a great amount of convenience and ease for the citizens' use (Gov Gateway). However, it is not known whether the citizens are adopting the services available to the. Additionally, as egovernment services are still under development, an investigation is needed to study whether or not the socio-economic determinants (Rogers, 1995) and the type of Internet access at home are affecting their awareness and adoption. Utilising the aforementioned reasoning as motivating factors for this research, the aim of this study is to conduct an empirical examination, which investigates the impact of socio-economic determinants on the adoption of a recent $U K e$ government initiative, the 'Government Gateway', that offers secure centralised registration for all e-government services available in the UK.

The paper is structured as follows. In the next section there is a theoretical justification for the underlying socio-economic variables while formulating hypotheses. Section 3 provides a brief discussion of the utilised research method. The findings are then presented and discussed in sections 4 and 5. Finally, a conclusion to the research is provided in the concluding section.

\section{Theoretical basis}

There are certain characteristics or variables that are found to be associated with an individual's innovativeness. Rogers (1995) termed such a group of characteristics or variables as socio-economic characteristics, which include age, education, occupation and income. Since these socio-economic characteristics are related to an individual's innovativeness, they affect the rate of adoption and diffusion of new innovations (Roger, 1995). These socio-economic variables 
have been widely applied to investigate a number of objects and issues within the information systems discipline such as the computer (Carveth and Kretchmer, 2004; Venkatesh et al. 2000), the Internet (Anderson and Tracy, 2001; Carveth and Kretchmer, 2004) and broadband adoption and its subsequent impact on users (Choudrie and Dwivedi, 2005; 2006). Given the wide applications of socioeconomic characteristics for examining the adoption of a number of aforementioned ICTs, their role is also imperative for examining the awareness and adoption of the Government Gateway.

Also adopters of an existing and related innovation or technology are likely to be more innovative than non-adopters (Roger, 1995). Hence adopters of existing technology are more likely to adopt emerging technologies and services as they possess a higher level of awareness about new developments and skills to perform behaviour. Therefore, by utilizing this reasoning it can be assumed that adopters of the Government Gateway are more likely to be broadband adopters than non-adopters.

According to the Diffusion of Innovation theory, the knowledge and persuasion stage comes before adoption of an innovation (Roger, 1995). That simply means that the more knowledge and awareness about innovation and benefits that is offered, the more likely that a faster adoption rate will be derived. Similarly, if more and more citizens are aware of the Government Gateway and its benefits, then they are more likely to adopt it. That suggests that awareness of the Government Gateway should be positively correlated with adoption of the Government Gateway.

\section{Research methodology}

Empirical research via a survey method is considered to be an appropriate approach to examining the adoption of broadband and the Government Gateway (Choudrie and Dwivedi, 2005b). Data on the adoption of broadband and the Government Gateway was randomly collected from citizens in the UK. In order to collect random data for the target population, a self-administered questionnaire was considered to be the most appropriate primary survey instrument in this investigation. Overall, the questionnaire used in this research contained 14 questions. These questions were divided into two categories: (1) multiple-choice questions addressing the socio-economic characteristics such as age, gender, education, occupation and income. (2) Yes/No questions were asked to establish whether or not the respondents were aware of the Government Gateway and if they had registered to access it.

Prior to dissemination of the final questionnaire, a pilot study was conducted to determine the response rate and learn of any discrepancies within the questions, which included determining whether the format of the questionnaire and questions were suitable. The pilot questionnaire was delivered via the postal service to a total of 200 randomly selected participants in December 2004. A total of 40 replies were obtained from the respondents within the specified 
duration. The majority of the respondents reported that the questionnaire was easily understandable and required 10 to 15 minutes for completion. Additionally, the majority of the respondents validated the content of the questionnaires, although minor changes to the final design of the questionnaire were undertaken based upon the received feedback, and a final questionnaire was developed.

The final questionnaires were sent using the postal service. A cover letter and a self-addressed prepaid return envelope were administered in the period between January and March 2005 to a total of 1600 household consumers in the UK. The collated data was analysed using SPSS version 11.5. This allowed the calculation of the response frequencies, percentages and chi-square values to analyze the variables determined by this research. It is important to mention that hereafter all significance level refers at 0.05 level.

Of the overall 1600 sent questionnaires, 358 usable replies were received within the specified periods. This implies that a response rate of $22.37 \%$ was obtained. To test the non-response bias, 200 questionnaires were sent to randomly selected non-respondents from an original sample in mid March 2005. From that, 40 questionnaire replies were received, comprising of 38 usable and two partially completed questionnaires. To test if the characteristics of respondents from original responses are similar to those of non-respondents, a chi-square $\left(\chi^{2}\right)$ test was conducted for the following demographic variables: age, gender and education (Fowler, 2002), Internet access at home, type of internet connection at home and Government Gateway adoption. The findings are illustrated in Table 1. The chi-square value is not significant for all six variables (Table 1). This suggests that those non-respondents who returned the completed questionnaire after reminder were similar to respondents from original responses.

Table 1 Test of significance for response bias

\begin{tabular}{llll}
\hline Variables & $\chi^{2}$ Value & $d f$ & Significance \\
\hline Age X Response Type & 6.904 & 5 & .228 \\
Gender X Response Type & .312 & 1 & .577 \\
Education X Response Type & 5.43 & 4 & .246 \\
Internet Access X Response Type & .419 & 1 & .518 \\
Type of Internet Connection X Response Type & 2.583 & 1 & .108 \\
Gov. Gateway Adoption X Response Type & 1.67 & 1 & .196 \\
\hline
\end{tabular}

\section{Findings}

Of the 358 responses, 308 (86 percent) respondents possessed Internet access at home, either using narrowband or broadband, and 50 (14 percent) stated that they do not have any means of Internet access at home. Of the 308 respondents who access the Internet at home, 207 (57.8 percent) represented the adopters of broadband and 101 (28.2 percent) represented the non-adopters (i.e. narrowband users). 


\subsection{Government Gateway adoption and non-adoption}

Since the focus of this research was upon the awareness and adoption of the Government Gateway, the next step to this research involved categorizing the respondents into: (i) adopters who have registered to the Government Gateway; and (ii) those who are aware of it but have not registered. Figure 1 illustrates these findings, which indicate that only 6 percent of the respondents of this sample had registered with the Government Gateway. Of the remaining 94 percent, 24 percent respondents stated that they are aware but have not yet registered, and the remaining 76 percent were not even aware of the Government Gateway (Figure 1). A binary correlation test was conducted to examine if awareness of the Government Gateway is associated with its adoption. The findings suggest that there was a significant positive correlation between awareness and adoption of the Government Gateway ( $\mathrm{r}=0.447, \mathrm{n}=358, p<$ .0005 , one-tailed).

Figure 1 Awareness and adoption of government gateway

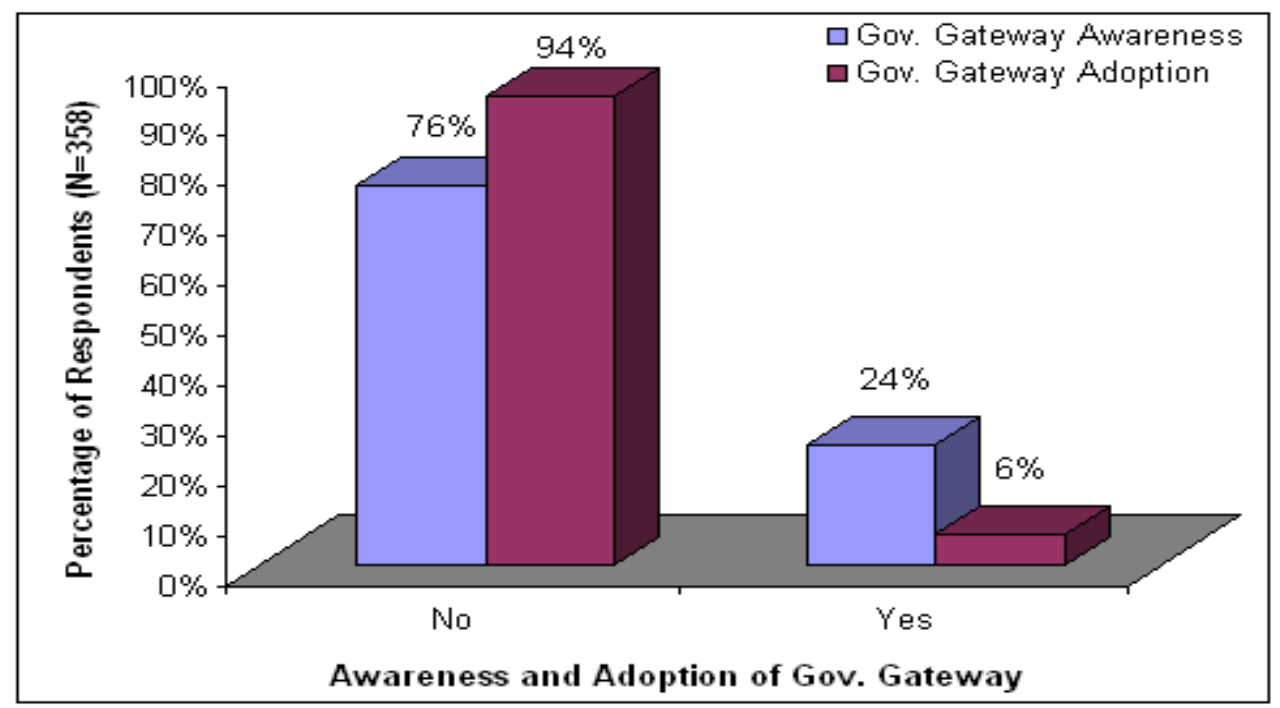

\subsection{Socio-economic attributes and adoption government gateway}

The effect of socio-economic characteristics such as age, gender, education, occupation and income on awareness and adoption of the Government Gateway is illustrated in figures 2 to 7 . In order to test if the differences caused by socioeconomic characteristics on awareness and adoption of the Government Gateway are significant, a chi-square $\left(\chi^{2}\right)$ test was conducted. The results of the $\chi^{2}$ test are summarised in Table 2 and will be presented in the following relevant sections.

\subsubsection{Age and Government Gateway awareness and adoption}

In terms of Government Gateway awareness, it was found that as the respondent age increases, the awareness of the Government Gateway increases as well 
(Figure 2), up to a point. Awareness declined after 54 years and only 12 percent respondents above the 65 years category were aware of the Government Gateway. The largest amount of awareness reported was for the 35 and 44 years age category. Findings from Pearson's chi-square test that is presented in Table 2 validate that there was a significant difference between the ages of respondents who were aware pf the Government Gateway and those who were not $\left(\chi^{2}=\right.$ $11.50, \mathrm{df}=5, p=.021)$.

Table 2 Summary of chi-square test

\begin{tabular}{lrrrr}
\hline \multicolumn{1}{c}{ Variables } & \multicolumn{4}{c}{ Chi-Square } \\
\multicolumn{1}{c}{ Government Gateway Awareness } & & $\chi^{2}$ Value & $d f$ & Sig. \\
& & & \\
Age X Government Gateway Awareness & 357 & 11.50 & 5 & .021 \\
Gender X Government Gateway Awareness & 355 & 2.74 & 1 & .048 \\
Education X Government Gateway Awareness & 341 & 13.25 & 4 & .005 \\
Income X Government Gateway Awareness & 347 & 7.22 & 7 & .203 \\
Occupation X Government Gateway Awareness & 345 & 10.22 & 5 & .035 \\
Type of Internet X Government Gateway Awareness & 308 & 7.15 & 1 & .004 \\
\multicolumn{1}{c}{ Government Gateway Adoption } & & & \\
Age X Government Gateway Adoption & 357 & 14.26 & 5 & .007 \\
Gender X Government Gateway Adoption & 355 & 5.67 & 1 & .008 \\
Education X Government Gateway Adoption & 341 & 7.21 & 4 & .062 \\
Income X Government Gateway Adoption & 347 & 8.70 & 7 & .137 \\
Occupation X Government Gateway Adoption & 345 & 18.15 & 5 & .002 \\
Type of Internet X Government Gateway Adopters & 308 & 3.50 & 1 & .046 \\
\hline
\end{tabular}

Legend: NVC= Number of Valid Cases, Sig.= Significance (1-sided)

In terms of Government Gateway adoption, it was found that as the respondent age increased, the adoption of the Government Gateway increases as well (Figure 2 ), again up to a point. The adoption rate declines considerably after 54 years and there were no respondents reported above the 65 years category. The majority of the adopters were between the 25 and 54 years age categories. The largest number of adopters reported was for the 45 and 54 years age category. The result from the chi-square test suggests that there was a significant difference between the age of Government Gateway adopters and non-adopters $\left(\chi^{2}=14.26, \mathrm{df}=5, p\right.$ $=.007)($ Table 2). 
Figure 2 Age differences on awareness and adoption of government gateway

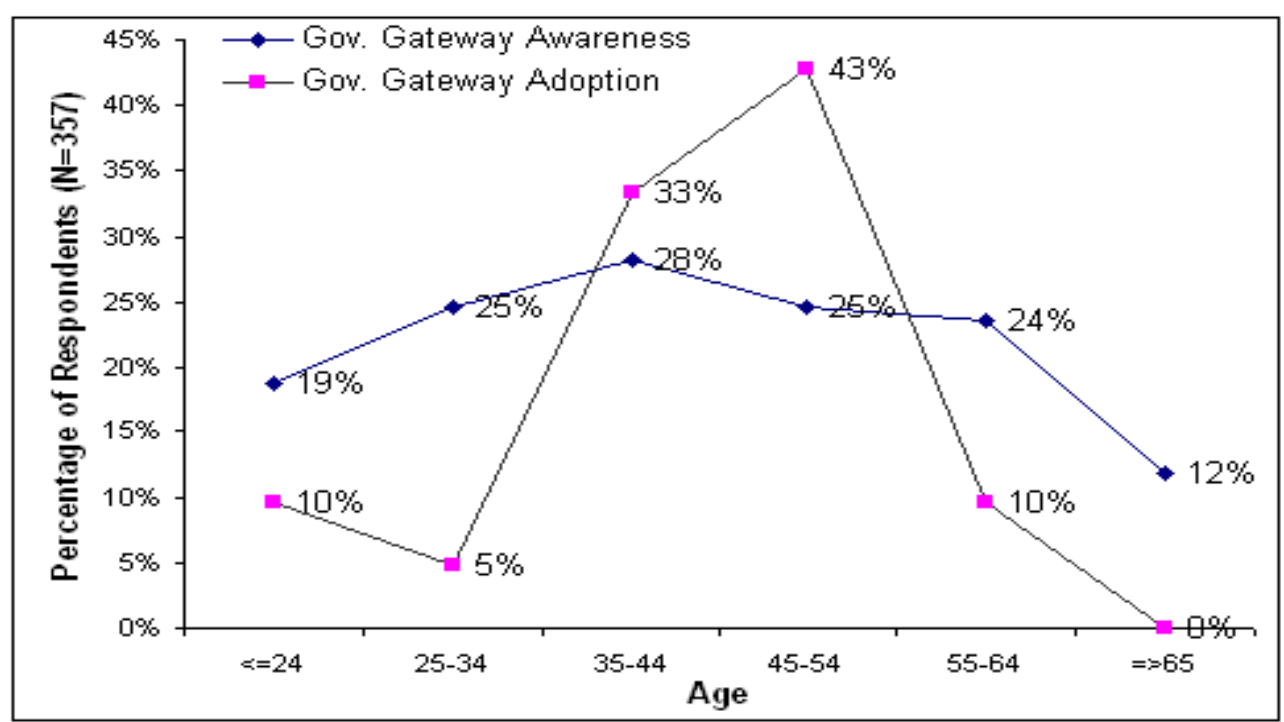

\subsubsection{Gender and Government Gateway awareness and adoption}

In terms of gender and Government Gateway awareness, Figure 3 illustrates that more male respondents (59\%) were aware of the Government Gateway than females $(41 \%)$. Pearson's chi-square test validates the notion that there was a significant difference between the number of males and females in terms of their awareness about Government Gateway $\left(\chi^{2}=2.74, \mathrm{df}=1, p=.048\right)$ (Table 2).

Figure 3 Gender differences on awareness and adoption of gov. gateway

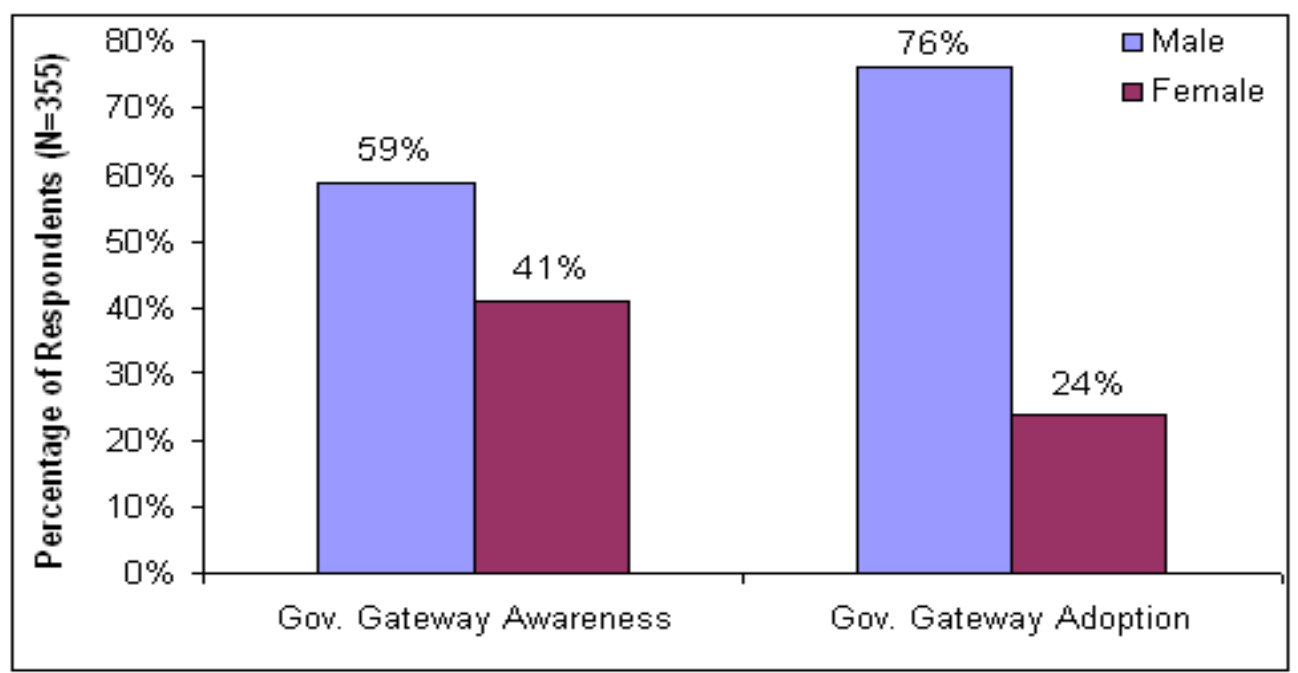


In terms of gender and Government Gateway adoption, Figure 3 illustrates that the adopters are more often male (76\%) rather than female (24\%). The findings from Pearson's chi-square test validate that there was a significant difference between the gender of Government Gateway adopters and non-adopters $\left(\chi^{2}=\right.$ 5.67, $\mathrm{df}=1, p=.008)($ Table 2).

\subsubsection{Education and Government Gateway awareness and adoption}

In terms of education and awareness of the Government Gateway, Figure 4 illustrates that as the respondent education level increases, the awareness of the government gateway increases as well. The largest amount of awareness was reported for the respondents who had achieved postgraduate study (43\%), followed by degree level (35\%). In contrast, only 11 percent of respondents who possessed A level and 5 percent of those educated to GCSE level were aware of the Government Gateway. Results from Pearson's chi-square test, presented in Table 2, suggest that there was a significant difference between the education of those respondents who were aware of the Government Gateway and those who were $\operatorname{not}\left(\chi^{2}=13.25, \mathrm{df}=4, p=.005\right)$.

Figure 4 Educational differences on awareness and adoption of Government Gateway

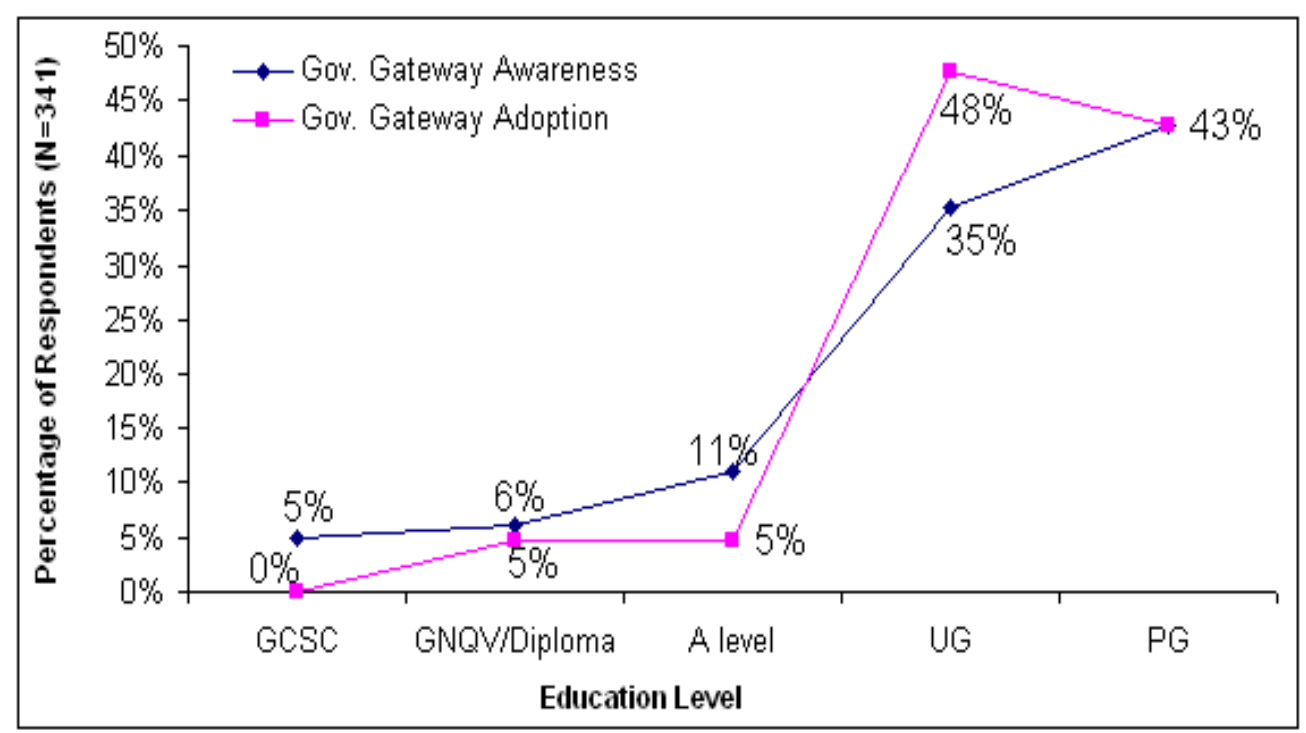

Figure 4 also offers an explanation of the educational attainment of the adopters of the Government Gateway. The findings suggest that the majority of adopters are educated to degree level (48\%), followed by a postgraduate $(43 \%)$ level of education. Only $10 \%$ of the total number of adopters surveyed possessed an education qualification below degree level, including 5 percent who have GNQV and 5 percent who have A levels. However, none of the respondents with GCSC 
had registered with the Government Gateway. Similar to the adopters, the majority of non-adopters also possess the higher level of education. Since both adopters and non-adopters have higher-level education, Pearson's chi-square test suggests that there was no significant difference between the education level of adopters and non-adopters of the Government Gateway $\left(\chi^{2}=7.21, \mathrm{df}=4, p=\right.$ .062) (Table 2).

\subsubsection{Occupation level and Government Gateway awareness and adoption}

In terms of occupation and awareness of the Government Gateway, Figure 5 illustrates that the respondents from higher occupational categories are more aware of the Government Gateway than the lower occupational categories (Figure 5). The largest degree of awareness reported was for the respondents from occupational level 'B' (36\%), followed by occupational category ' $E$ ' $(31 \%)$. In contrast, only 5 percent of the respondents from ' $\mathrm{C} 2$ ' and 1 percent from the 'D' category were aware of the Government Gateway. Results from Pearson's chi-square test in Table 2 suggest that there was a significant difference between the occupation of respondents who were aware of the Government Gateway and those who were not $\left(\chi^{2}=10.22, \mathrm{df}=5, p=.035\right)$.

Figure 5 Occupational differences on awareness and adoption of the Government Gateway

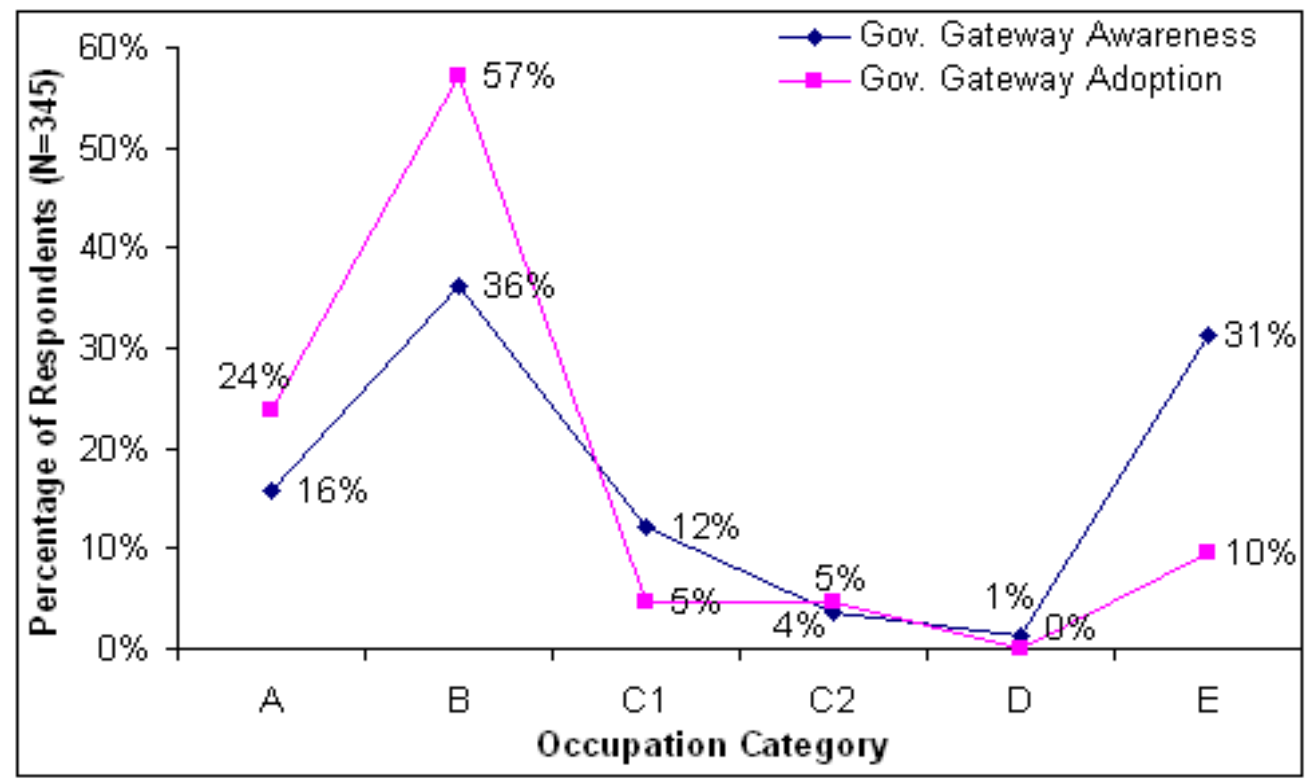

Figure 5 illustrates the occupational categories for adopters of the Government Gateway. This shows that no respondents from category ' $\mathrm{D}$ ' have adopted the Government Gateway. Categories ' $\mathrm{C} 1$ ' and ' $\mathrm{C} 2$ ' only represent 5 percent of the adopters each. Category ' $\mathrm{E}$ ' characterizes only 10 percent of the adopters. The prime number of adopters who had registered to the common gateway belonged 
to occupation category 'B' $(57 \%)$, followed by social class 'A' $(24 \%)$. The findings from Pearson's chi-square test validate that there was significant difference between the occupational categories of adopters and non-adopters of the Government Gateway $\left(\chi^{2}=18.155, \mathrm{df}=5, \mathrm{p}=.002\right)$ (Table 2).

\subsubsection{Annual income and Government Gateway awareness and adoption}

With regard to awareness of the Government Gateway, Figure 6 suggests no clear pattern. All income categories represent similar numbers of respondents who were aware of the Government Gateway. Pearson's chi-square test suggests that there was no significant difference between the income level of respondents who were aware of the Government Gateway and those who were not $\left(\chi^{2}=7.22\right.$, $\mathrm{df}=7, p=.203)($ Table 2$)$.

With regard to Government Gateway adoption, Figure 6 suggests that no respondents from the $<=10 \mathrm{~K}$ category had registered to the Government Gateway. All the other income categories represented both the adopters and nonadopters of the Government Gateway; however, the number of adopters was much lower than that of non-adopters. The findings from the chi-square test suggest that there was no significant difference between the income level of adopters and non-adopters of the Government Gateway $\left(\chi^{2}=8.70, \mathrm{df}=7, \mathrm{p}=\right.$ .137) (Table 2).

Figure 6 Income differences on awareness and adoption of the Government Gateway

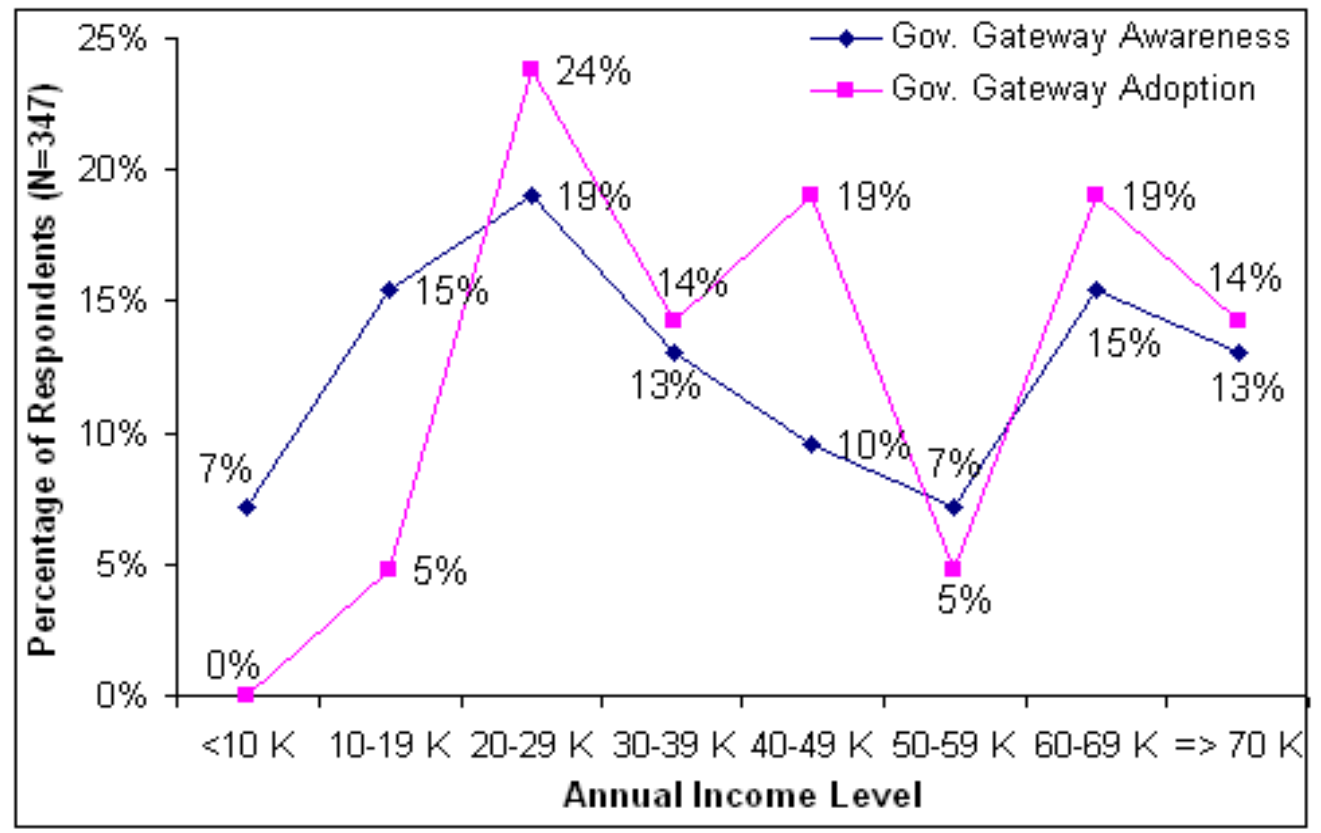




\subsection{Broadband access and Government Gateway awareness and adoption}

Figure 7 illustrates the differences amongst those who possess broadband access at home and are aware of the Government Gateway. More respondents with broadband access at home possess awareness of the Government Gateway (79\%) than those who access the Internet at home using a dial-up connection (21\%). Results from the chi-square test suggest that there was a significant difference between broadband access at home and awareness of the Government Gateway $\left(\chi^{2}=7.15, \mathrm{df}=1, p=.004\right)($ Table 2$)$.

Figure 7 Effect of broadband adoption on Government Gateway adoption

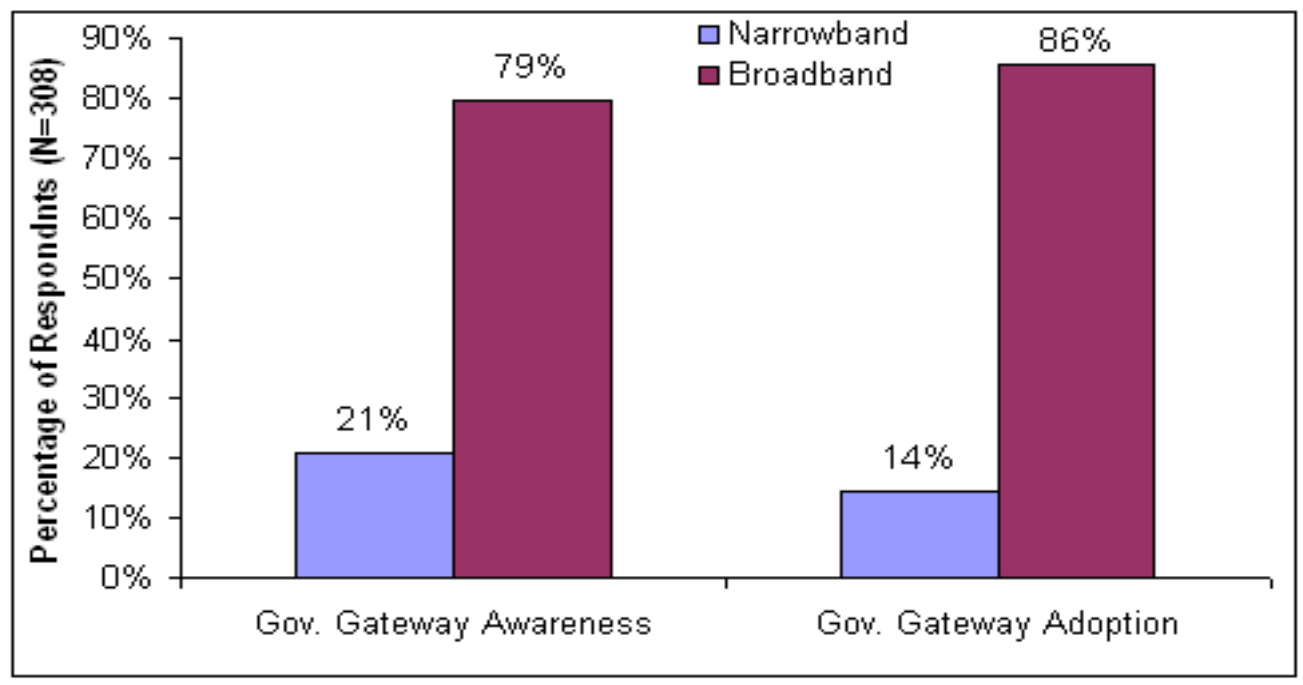

Figure 7 also illustrates the correlation between those who possess broadband access at home and those who have adopted the Government Gateway. Respondents with broadband access at home possess higher adoption rates of the Government Gateway (86\%) than those who access the Internet at home using a dial-up connection (14\%). This result suggests that the diffusion and adoption of the Internet at home will directly affect the adoption and diffusion of new electronic services including e-government. The findings from the chi-square test validate this and suggest that there was a significant difference between broadband access at home and adoption and non-adoption of the Government Gateway $\left(\chi^{2}=3.50, \mathrm{df}=1, p=.046\right)$ (Table 2).

A binary correlation test was also conducted to examine if there was a correlation between the type of Internet connection and Government Gateway awareness and adoption. The findings suggest that there was a significant positive correlation between the type of Internet connection and Government Gateway awareness $(\mathrm{r}=$ $0.152, \mathrm{n}=308, p=.004$, one-tailed) and adoption $(\mathrm{r}=0.107, \mathrm{n}=308, p<.031$, one-tailed). 


\section{Discussion}

Table 2 illustrate that of the five socio-economic characteristics selected for this study, four of them (age, gender, education and occupation) were significant in terms of awareness of the Government Gateway. However, as was expected, income has no significant effect on awareness of the Government Gateway. In comparison to awareness, only three socio-economic characteristics (age, gender and occupation) differentiated Government Gateway adopters significantly from non-adopters, whilst education and income were non-significant. Apart from the socio-economic characteristics, having broadband at home is also a factor that is promoting the awareness and adoption of new e-government services and application such as the Government Gateway. This study provides evidence that, although socio-economic characteristics are playing an important role in the adoption and diffusion of ICTs, the magnitude of their effects differ according to the nature of the products and/or services available.

Government Gateway awareness and adoption was reported as high in the lower age group but low in the older age group (Figure 2). Earlier anecdotal evidence suggested that the older aged people are less likely to subscribe to ICTs, which was supported by the findings of this research. A possible explanation is that the older aged respondents do not possess the basic skills needed to operate computers, and a majority of them do not have computers at home because they do not consider a need for them. A majority of the adopters belonged to the age group of 25-54 years (Figure 2). This is because this age group is likely to be more educated and have a high level of occupation; therefore, a new innovation like the Government Gateway is more likely to be adopted and diffused first within this segment of the age group (Roger, 1995).

Awareness and adoption of the Government Gateway does require computer and Internet skill, and the knowledge to use it. Webster (1995) argued that men dominate technological knowledge, practices and institutions. He claimed that this may create Information Technology, which is often alien to women and that policy is therefore forced to address their exclusion from technology at educational, occupational and organizational levels. Even after 10 years, Webster's (1995) concern is reflected in the finding that illustrates significant gender differences between adopters and non-adopters of the Government Gateway (Figure 3).

It was expected that a higher number of educated respondents are more likely to be aware of the Government Gateway than the respondents with a lower level of education. The findings of this study are in line with the hypothesis. The findings illustrated in Figure 4 suggest that the awareness of the Government Gateway was reported at its minimum with those respondents that had achieved a GCSE level of education. In contrast, the highest awareness was reported amongst respondents with a degree or a PG level education. Contrastingly, adoption of the Government Gateway is not a utility tool for office work or for education. Hence this is not an effective or significant socio-economic characteristic to explain the differences between adopters and non-adopters of the Government Gateway. 
The findings illustrated in Figure 5 suggest that the majority of Government Gateway adopters belong to a higher occupational category such as 'A' or 'B'. Although it was not expected that respondents from the lowest occupational category, which was 'E', would have an awareness of the Government Gateway, the findings suggest that the second largest proportion of awareness belongs to this category. This can be attributed to the following reasons. First, as Rice (1997) argued, an anomaly in the occupational category may occur when a respondent who belongs to ' $\mathrm{B}$ ' obtains redundancy in employment and then immediately drops to the ' $\mathrm{E}$ 'section. This is despite the fact that the disposable income could have increased due to redundancy payments (Rice, 1997). Freeman (1995) also discusses the link between unemployment and the diffusion of ICTs. It was reported in this study that unemployed respondents who were placed in category ' $E$ ' are engaged in re-skilling in order to achieve white-collar jobs (Freeman, 1995). Since having ICTs facilitates the process of re-skilling, it is more likely that such unemployed respondents become aware of, and keep track of, new technological developments such as the Government Gateway. Adoption of the Government Gateway is clearly driven by higher occupational categories, whilst lower categories including ' $E$ ' mainly consist of non-adopters. This is because it does not offer any direct help in gaining employment or education. Reasons for why respondents from higher occupational categories are adopting the Government Gateway is the 'ease of access' and the convenience that it offers to busy professionals.

The statistics presented in Figure 6 suggest that the income level is not a good predictor for both awareness and adoption of the Government Gateway. This is in line with the argument presented in the theoretical foundation section. The reason is simple; adoption of the Government Gateway does not require any financial investment, hence respondents from all income levels can register if they have the necessary skills and knowledge for registering with the Government Gateway.

\section{Conclusions and implications}

This paper empirically examined the impact of socio-economic determinants on the adoption of a recent UK e-government initiative, the 'Government Gateway'. Five socio-economic characteristics (i.e. age, gender, education, income and occupation) were utilised to provide insights of Government Gateway awareness and adoption. The study concludes that the demographic characteristics of consumers such as age, gender, education and occupation have an imperative role in understanding the adoption of emerging technologies. However, not all five demographic characteristics are effective in all of the situations. This study concludes that the impact of a particular socio-economic characteristic on adoption and diffusion is dependent upon the nature and utility of the technologies in question. For example, age, gender, education and occupation are important variables that are significant for the awareness issue but income is not. Contrastingly, for Government Gateway adoption, age, gender and occupation 
are important variables but education and income are not. The findings clearly suggest that there is an unequal or heterogeneous adoption or a digital divide in various dimensions including age, gender, income, occupation and education.

In order to reduce the socio-economic gap during the diffusion process, Rogers (1995) suggested that the change agent should follow the strategy of greatest resistance, so that greater attention is paid towards a diffusion policy that encourages lower socio-economic groups. That means that, in the case of the Government Gateway, non-adopter categories such as older aged people, females, and people with lower education, occupation and income should be targeted first. Hence, an important consideration for government agencies and policy makers responsible for e-government deployment is to encourage the aforementioned segments of society that are slow in adopting emerging egovernment services like the Government Gateway. By doing so they will help to reduce the socio-economic gaps and the digital divide. Also, government agencies should try to remove the barriers that may inhibit members of socioeconomic groups from adopting innovation such as the Government Gateway. For example, the older aged people are not adopting these e-government services for two important reasons (Choudrie and Dwivedi, 2005a): (i) the majority of older aged people do not have the skills to operate the computer and the Internet; (ii) they are not aware of the potential benefits of e-government services and new developments. Therefore, the key challenge for policy makers is to implement ways of involving the older aged citizens to the mainstream information society.

\subsection{Limitations and future research directions}

In this survey the sample was drawn from the overall UK population; therefore generalizations can be made. However, the limitation of this national survey was that the response rate was low; therefore, the confidence level in findings was limited. However, conducting a non-response bias test led to surmounting of this limitation (Fowler, 2002) and illustrates reliability and confidence in the findings of this study.

Since this was a self-administered survey, by keeping the response rate in mind (Fowler, 2002) only closed ended questions were included. It restricted the researcher's ability to ask open-ended questions (Fowler, 2002), which might have assisted in offering a better understanding of why particular segments of society are adopting or not adopting government gateway and other emerging egovernment services. To overcome this limitation, future studies may employ data collection methods such as, interviews or focus groups that will examine the adoption and diffusion of new ICTs such as, e-Government services.

This study further emphasizes the suggestions made by previous studies (Choudrie and Dwivedi, 2005b, 2006). That is, in order to highlight crosscultural differences it will also be interesting to compare the demographic characteristics of UK e-government consumers to other users of countries such as, the United States of America, Canada and Australia. Due to the unavailability of such studies, it was not possible to make such a comparison within this 
research; however, it is recommended that future research should investigate such issues.

\section{References}

Anderson, B. and Tracey, K. (2001) 'Digital living: The impact (or Otherwise) of the Internet on everyday life', American Behavioral Scientist, Vol. 45, No. 3, pp. 456-475.

Bose, R. (2004) 'E-government infrastructure and technologies for education and training', Electronic Government, an International Journal, Vol. 1, No. 4, pp. 349-361.

Carter, L. and Belanger, F. (2004) 'The influence of perceived characteristics of innovating on e-government adoption', Electronic Journal of $e$ Government, Vol. 2, No. 1, pp. 11-20.

Carveth, R. and Kretchmer, S.B. (2002) 'The digital divide in Western Europe: problems and prospects', Informing Science, pp. 239-249.

Chadwick, A. and May, C. (2003) 'Interaction between states and citizens in the age of the Internet: e-Government in the United States, Britain, and the European Union', Governance, Vol.16, No. 2, pp. 271-298.

Choudrie, J. and Dwivedi, Y.K. (2006) 'A comparative study to examine the socio-economic characteristics of broadband adopters and non-adopters', Electronic Government: An International Journal, Vol. 3, No 3, pp.272288.

Choudrie, J. and Dwivedi, Y.K. (2005a) 'The demographics of broadband residential consumers of a British local community: The London Borough of Hillingdon', Journal of Computer Information Systems, Vol. 45, No. 4, pp. 93-101.

Choudrie, J. and Dwivedi, Y. K. (2005b) 'Investigating the research approaches for examining technology adoption issues', Journal of Research Practice, Vol. 1, No. 1, Article D1. http://jrp.icaap.org/content/v1.1/choudrie.pdf accessed 20 June 2005.

Choudrie, J. and Ghinea, G. (2005) 'Integrated views of e-government website usability: perspectives from users and web diagnostic tools', Electronic Government, an International Journal, Vol. 2, No. 3, pp. 318-333.

Fowler, F.J. (2002) Survey Research Methods, London: SAGE Publications Inc.

Freeman, C. (1995) 'Unemployment and the diffusion of information technologies: the two-edged nature of technical change', Policy Paper No. 32, ESRC.

Ifinedo, P. and Davidrajuh, R. (2005) 'Digital divide in Europe: assessing and comparing the e-readiness of a developed and an emerging economy in the Nordic region', Electronic Government, an International Journal, Vol. 2, No. 2, pp. 111-133. 
Gefen, D., Warkentin, M., Pavlou, P.A. and Rose, G.M. (2002) 'E-government adoption', In Proceedings of the eighth Americas Conference on Information Systems.

George, K. (2004) 'Network analysis of disconnect in the hollow state: the case of e-government services portals', In Proceedings of the $12^{\text {th }}$ European Conference on Information Systems, Turku, Finland, June 14-16.

Government Gateway available at http://www.gateway.gov.uk/, 2004.

Marche, S. and McNiven, J.D. (2003) 'E-government and E-governance: the future isn't what it Used to be', Canadian Journal of Administrative Sciences, Vol. 20, No. 1, pp. 74.

Mason, S.M. and Hacker, K.L. (2003) 'Applying communication theory to digital divide research', IT \& Society, Vol. 1, No. 5, pp. 40-55.

Northrup, T.A. and. Thorson, S.J. (2003) 'The web of governance and democratic accountability', In Proceedings of the 36th Hawaii International Conference on System Sciences (HICSS).

RAND EUROPE (2003) 'Benchmarking e-Government in Europe and the US', available at http://www.rand.org/publications/MR/MR1733/MR1733.pdf

Rice, C. (1997) Understanding Customers, Oxford: Butterworth-Heinemann.

Rogers, E.M. (1995) Diffusion of Innovations, New York: Free Press.

Venkatesh, A., Chuan-Fong, Shih, E. and Norman, C. (2000) 'A longitudinal analysis of computing in the home census data 1984-1997', In Home informatics and Telematics: Information, Technology and Society, Sloane and Felix van Rijn (Eds), pp. 205-215.

Webster, J. (1995) 'Information Technology, Women and Their Work: Research Findings and Policy Issues', Policy Research Paper No. 30, ESRC.

Yttersad, P. and Watson, R. (1996) 'Teledemocracy: Using Information Technology to Enhance Political Work', MIS Quarterly, Vol. 20, No. 3.

Yang, J. and Paul, S. (2005) 'E-government application at local level: issues and challenges: an empirical study', Electronic Government, an International Journal, Vol. 2, No. 1, pp. 56-76.

$\mathrm{Yu}$, C.C. and Wang, H.I. (2004) 'Digital divide in Taiwan: evidence, comparisons and strategies', Electronic Government, an International Journal, Vol. 1, No. 2, pp. 179-197. 